\title{
Papers
}

\section{Randomised study of long term outcome after epidural versus non-epidural analgesia during labour}

\author{
Charlotte J Howell, Tracy Dean, Linda Lucking, Krysia Dziedzic, Peter W Jones, Richard B Johanson
}

\begin{abstract}
Objective To determine whether epidural analgesia during labour is associated with long term backache. Design Follow up after randomised controlled trial. Analysis by intention to treat.

Setting Department of obstetrics and gynaecology at one NHS trust.

Participants 369 women: 184 randomised to epidural group (treatment as allocated received by 123) and 185 randomised to non-epidural group (treatment as allocated received by 133). In the follow up study 151 women were from the epidural group and 155 from the non-epidural group.

Main outcome measures Self reported low back pain, disability, and limitation of movement assessed through one to one interviews with physiotherapist, questionnaire on back pain and disability, physical measurements of spinal mobility.

Results There were no significant differences between groups in demographic details or other key characteristics. The mean time interval from delivery to interview was 26 months. There were no significant differences in the onset or duration of low back pain, with nearly a third of women in each group reporting pain in the week before interview. There were no differences in self reported measures of disability in activities of daily living and no significant differences in measurements of spinal mobility.
\end{abstract}

Conclusions After childbirth there are no differences in the incidence of long term low back pain, disability, or movement restriction between women who receive epidural pain relief and women who receive other forms of pain relief.

\section{Introduction}

Epidural analgesia in labour is used by about 100000 women in Britain each year. ${ }^{1}$ However, not much is known on long term effects of this form of pain relief, and before this study anecdotal or case series had concentrated on more severe side effects, such as extremely rare neurological complications. ${ }^{2}$

There have been several studies into back pain and epidural analgesia (table 1). MacArthur et al first suggested that epidural analgesia might be associated with low back in $1990 .^{3}$ They carried out a postal questionnaire survey of 12000 women who had delivered in Birmingham between 12 months and 9 years earlier. They found an unexpected association between the use of epidural pain relief for labour and long term low back pain (lasting more than three months). They were unable to make any assessment of the severity or aetiology of the low back pain. The authors were aware that this association might not be causal, and they attempted to control for possible confounding factors by statistical adjustment. Despite these adjustments, the

Table 1 Previous research into back pain and epidural analgesia in labour

\begin{tabular}{|c|c|c|c|c|}
\hline Study & Design* & $\begin{array}{l}\text { No of } \\
\text { participants }\end{array}$ & $\begin{array}{l}\text { Result for backache } \\
\text { (epidural } v \text { no epidural) }\end{array}$ & Authors' conclusion \\
\hline MacArthur, $1990^{3}$ & $\begin{array}{l}\text { Retrospective postal } \\
\text { questionnaire }\end{array}$ & 11701 & $18.9 \% \vee 10.5 \%$ at 6 weeks & $\begin{array}{l}\text { Relation between backache and epidural } \\
\text { analgesia is probably causal }\end{array}$ \\
\hline Russell, $1993^{4}$ & $\begin{array}{l}\text { Retrospective questionnaire plus } \\
\text { outpatient consultation }\end{array}$ & 1015 & $17.8 \%$ v $11.7 \%$ at 6 months & $\begin{array}{l}\text { Though new long term backache is reported } \\
\text { more commonly after epidural analgesia in } \\
\text { labour it tends to be postural and not severe }\end{array}$ \\
\hline MacArthur, $1993^{5}$ & $\begin{array}{l}\text { Data extraction from } 1990 \text { survey } \\
\text { paper and re-examination }\end{array}$ & 1141 & $18.6 \% \vee 9.2 \%$ at 6 months & Association with backache is real \\
\hline Breen, $1994^{16}$ & $\begin{array}{l}\text { Prospective interview and follow } \\
\text { up by postal questionnaire }\end{array}$ & 1042 & $44 \% \vee 45 \%$ at $1-2$ months & $\begin{array}{l}\text { Epidural analgesia for labour and delivery did } \\
\text { not seem to be associated with back pain 1-2 } \\
\text { months postpartum }\end{array}$ \\
\hline Macarthur, $1995^{17}$ & $\begin{array}{l}\text { Prospective cohort study with } \\
\text { follow up }\end{array}$ & 329 & $\begin{array}{l}14 \% \vee 7 \% \text { at } 6 \text { weeks (relative } \\
\text { risk } 2.22,95 \% \mathrm{Cl} 0.89 \text { to } 5.53 \text { ) }\end{array}$ & $\begin{array}{l}\text { Women who underwent epidural analgesia } \\
\text { during delivery had increased incidence of low } \\
\text { back pain only on first day after delivery }\end{array}$ \\
\hline MacLeod, $1995^{6}$ & $\begin{array}{l}\text { Retrospective postal } \\
\text { questionnaire }\end{array}$ & 2065 & $26.2 \% \vee 1.7 \%$ at 1 year & $\begin{array}{l}\text { Association between backache and epidural } \\
\text { may be causal but bias may be present. } \\
\text { Controlled randomised study warranted }\end{array}$ \\
\hline Macarthur, $1997^{15}$ & $\begin{array}{l}\text { Retrospective telephone } \\
\text { questionnaire }\end{array}$ & 329 & $\begin{array}{l}10 \% \text { (chose epidural) } v 14 \% \\
\text { (chose not to have) at } 1 \text { year }\end{array}$ & $\begin{array}{l}\text { No increased risk of back pain in women who } \\
\text { had used epidural analgesia }\end{array}$ \\
\hline
\end{tabular}

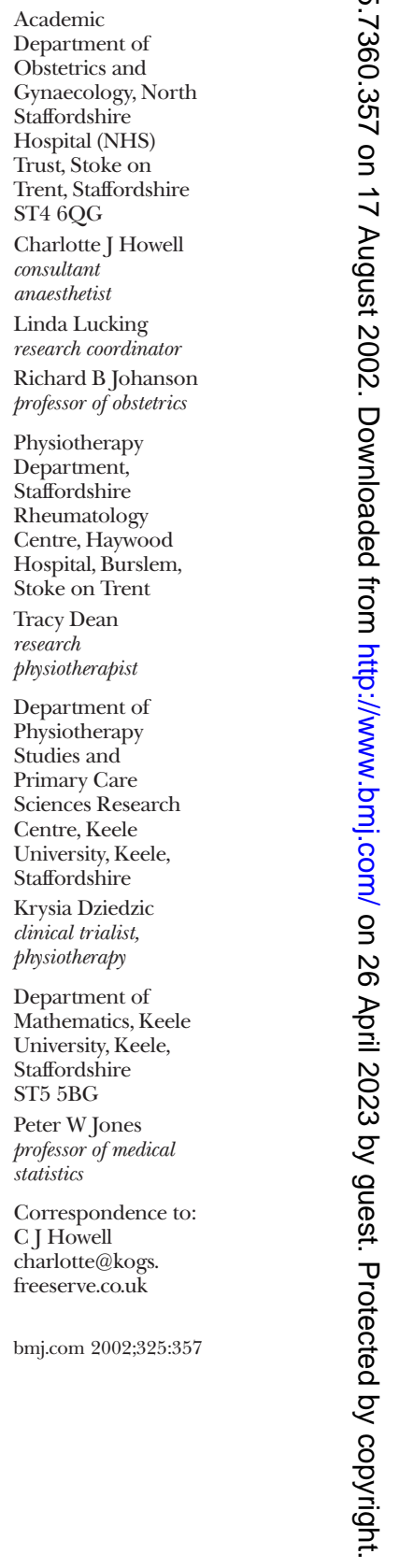

${ }^{*}$ None of these studies was randomised. 
Table 2 Comparability of women allocated to receive epidural analgesia or other form of pain relief during labour. Figures are means (SD) unless stated otherwise

\begin{tabular}{lcc} 
& Epidural $(\mathbf{n}=\mathbf{1 5 1})$ & Non-epidural $(\mathbf{n}=\mathbf{1 5 5})$ \\
\hline Maternal age (years) & $24.4(5.1)$ & $23.5(4.7)$ \\
\hline No (\%) with subsequent pregnancy & $36(24)$ & $35(23)$ \\
\hline $\begin{array}{l}\text { Time since delivery of index } \\
\text { pregnancy (months) }\end{array}$ & $26.6(12.5$, range 11-62) & $25.9(12.1$, range 12-62) \\
\hline Gestation at delivery (weeks) & $40(1.6)$ & $40(1.5)$ \\
\hline Birth weight (g) & $3440(385)$ & $3429(490.9)$ \\
\hline No (\%) with spontaneous labour & $125(83)$ & $122(79)$ \\
\hline
\end{tabular}

association between epidural pain relief for labour and the reporting of long term low back pain remained.

In a further retrospective observational study Russell et al found that $18 \%$ of women who received epidural analgesia had long term low back pain compared with $12 \%$ of those who used other forms of pain relief. ${ }^{4}$ Although there were suggestions that the excess low back pain might stem from a "popular notion that epidurals cause long term backache," MacArthur et al maintained that the association was real. ${ }^{5}$ Two years later, MacLeod et al, in another retrospective study, reported an even greater difference, with $26 \%$ of women who had epidurals for analgesia complaining of low back pain compared with only $2 \%$ in the non-epidural group. ${ }^{6}$

Given the great human, medical, and economic costs of chronic low back pain ${ }^{7}$ we considered that a prospective controlled study with objective assessment of long term outcome was urgently needed. We had already undertaken a randomised controlled trial of epidural and non-epidural analgesia in labour, in which we examined the immediate effects of the different forms of analgesia on progress of labour, satisfaction, and health after childbirth. ${ }^{8}$ We used the same general health questionnaire as MacArthur et al, ${ }^{3}$ which incorporated questions on low back pain. However, this did not allow an objective assessment of any back pain in terms of severity or the interference with mobility and activities of daily living.

We investigated long term differences in self reported and objective measures of low back pain between women who received epidural pain relief and those who received other forms of pain relief during labour.

\section{Methods}

Participants

For the original pain relief study we had recruited 369 primigravidas with a cephalic presentation at term. All these women were invited to participate in this follow up study (151 from the epidural group and 155 from the non-epidural group agreed to participate). In the original study 184 women were randomised to receive an epidural and 123 received it, and 185 were randomised to other methods of pain relief but 52 had an epidural (see figure). The study had local ethics committee approval, and all women had given signed informed consent to participate.

\section{Procedures}

Assessment of low back pain is complex as it involves the patient's personal and subjective experience of pain and disability as well as objective assessment of physical impairment. ${ }^{7}$ We used the Roland and Morris question- naire, which has been validated for assessing disability in activities of daily living due to low back pain.

We chose objective physical measurements that had previously been shown to identify those patients with low back pain and that were significantly associated with self reported disability in activities of daily living. ${ }^{10}$ The range of movements included straight leg raising, spinal flexion and extension, lateral flexion, and ability to sit up. Additional measurements included the modified Schober distance and the fingertip to floor method of assessing forward bending. ${ }^{711}{ }^{12}$ Before the study started we standardised assessment and carried out training to reduce intraobserver variability. TD undertook all assessments and was blinded to both the original group allocation and the method of pain relief actually received. Inevitably some women revealed this information during the course of the interview, and this was recorded.

The study ran from September 1995 to December 1997 (recruitment to the original pain relief study ended in September 1996). We contacted women who had taken part in the pain relief study and had given birth over 12 months previously. In previous studies researchers have found it difficult to get women to come to hospital for follow up assessments ${ }^{4}$ so we usually interviewed women in their own homes but appointments could be arranged at the hospital if this was more convenient. When a woman did not want to participate in a face to face interview we used a telephone interview or a postal questionnaire.

\section{Power calculations and analysis}

With 150 women in each group we calculated that we could be $80 \%$ confident of detecting (at $\mathrm{P}=0.05$ ) a clinically significant $10 \%$ difference in objective measurements of low back pain at two years. ${ }^{3}$

We analysed data on an intention to treat basis. Continuous data are expressed as mean (SD), and we assessed differences with $t$ tests. Frequency data were

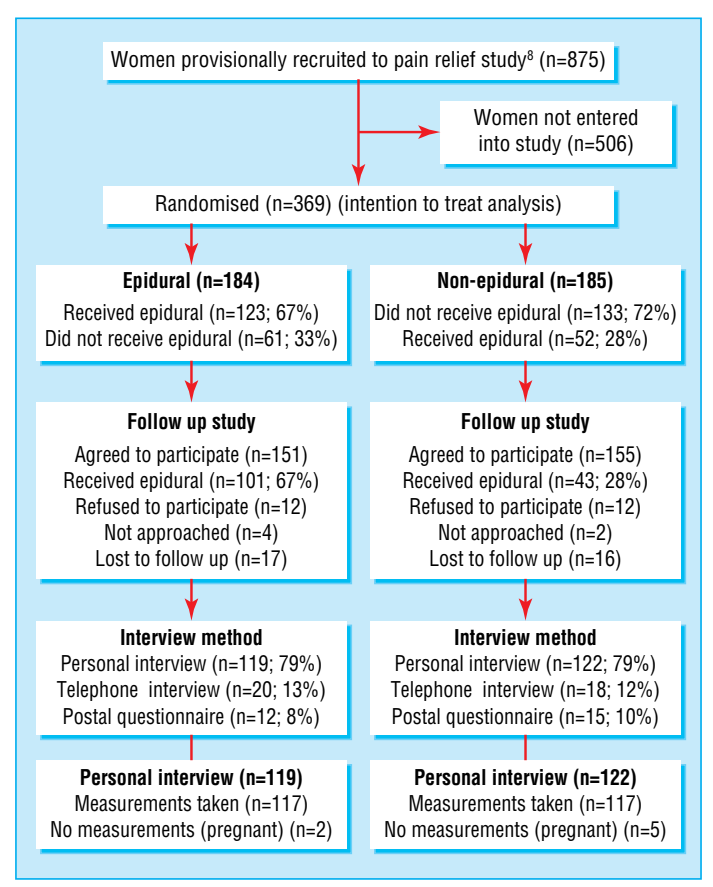

Flow chart showing entry into follow up study 
Table 3 Women's answers to pain questionnaire according to allocation to epidural analgesia or other method of pain relief during labour. Figures are numbers of women

\begin{tabular}{|c|c|c|}
\hline & Epidural $(n=151)$ & Non-epidural $(n=155)$ \\
\hline Experienced back pain & 115 & 112 \\
\hline Pain began during pregnancy & 87 & 83 \\
\hline \multicolumn{3}{|l|}{ Pain began after delivery (time): } \\
\hline Shortly after & 14 & 12 \\
\hline $1-2$ months & 2 & 1 \\
\hline $2-4$ months & 4 & 2 \\
\hline 6-12 months & 0 & 1 \\
\hline $12-18$ months & 0 & 1 \\
\hline 18-24 months & 0 & 1 \\
\hline$>2$ years & 1 & 0 \\
\hline Some other time & 7 & 11 \\
\hline Pain lasted $>1$ year & 47 & 64 \\
\hline Still experiencing pain now & 64 & 70 \\
\hline Pain in past week & 46 & 47 \\
\hline \multicolumn{3}{|l|}{ Last episode of pain: } \\
\hline Very bad/unbearable & 17 & 13 \\
\hline Moderate/quite bad & 67 & 67 \\
\hline Little pain & 30 & 25 \\
\hline No reply & 1 & 7 \\
\hline \multicolumn{3}{|l|}{ Most common site of pain: } \\
\hline Lumbar/upper sacral region & 90 & 76 \\
\hline Multiple areas & 19 & 20 \\
\hline Other areas & 4 & 11 \\
\hline Site not specified & 2 & 5 \\
\hline $\begin{array}{l}\text { Pain alters during } \\
\text { menstruation }\end{array}$ & 26 & 25 \\
\hline
\end{tabular}

analysed with the StatXact Turbo package (CYTEL, Cambridge, MA, USA).

\section{Results}

Table 2 shows basic data for the two groups. These data reflect the validity of the original randomisation. The mean time since delivery of the index pregnancy was over two years in both groups.

The figure shows the entry flow for the study. The proportion of women who received their allocated method of pain relief in the original study was similar in both groups, as were the proportions by method of follow up and the proportions in which the assessor remained blind to the original method of analgesia (epidural 126/151 v non-epidural 138/155).

The incidence of self reported low back pain during or after pregnancy was high (table 3). There were no significant differences in terms of the timing of onset. Back pain was common in both groups and more women reported severe pain in the epidural group, but pain lasting more than one year, persistent pain, and recent pain were all more common among women who had not had an epidural.

We measured a range of movements in 117 of 119 women in the epidural group who were interviewed and 117 of 122 in the non-epidural group (table 4). The seven women who were not examined at all were pregnant at the time of the assessment, and measurements were omitted at the request of the woman or on the advice of the research physiotherapist. There were no significant differences between the groups in any of the measurements of mobility. There were also no differences in responses to questions about everyday tasks that may be more difficult in the presence of low back pain (table 5).

\section{Discussion}

In this controlled comparison of the long term effects of epidural and non-epidural analgesia we found no significant differences in self reported low back pain or disability and in objective measurements of spinal mobility after more than two years. The validity of these findings is affirmed by the randomised study design, the objective measures of outcome, and the high follow up rate.

\section{Limitations}

The interpretation of our findings is limited by the number of crossovers between groups. This is inevitable in trials that compare epidural and non-epidural pain relief ${ }^{13}$ but was lower in our study than in others. This study could therefore be considered as showing the differences between liberal and restricted use of epidural analgesia in labour. The absolute difference in epidural use was 40\%. Despite the real life crossover between groups we found a significant association between use of epidural analgesia and the rate of assisted delivery, being 30\% compared with $19 \%$ in the non-epidural group. ${ }^{8}$ If an increased incidence of low back pain was also attributable to the use of epidurals, it too could have been shown despite the crossover. Our analysis was on an intention to treat basis for valid scientific reasons ${ }^{14}$ and also because this is the standpoint from which women will approach labour. They may be intending to use particular forms of analgesia, but in the real world some women may find non-epidural methods insufficient or may be managing so well that they do not use the epidural that they planned. The findings are also limited by the moderate numbers of women included, meaning that rare events of harm could not have been reliably detected.

Table 4 Roland and Morris questionnaire and measurements of movement. Figures are means (SD) unless stated otherwise

\begin{tabular}{|c|c|c|c|}
\hline & Epidural $(n=119)$ & Non-epidural $(n=122)$ & $\begin{array}{l}95 \% \mathrm{Cl} \text { for difference in } \\
\text { means or } \%\end{array}$ \\
\hline Modified Schober distance $(\mathrm{cm})$ & $6.9(1.3), \mathrm{n}=115$ & $6.8(1.3), n=116$ & -0.237 to 0.437 \\
\hline Fingertip to floor distance $(\mathrm{cm})$ & $1.8(5.6), \mathrm{n}=117$ & $2.1(5.8), n=117$ & -1.77 to 1.17 \\
\hline Right lateral flexion $(\mathrm{cm})$ & $22.1(4.7), n=116$ & $22.6(4.4), \mathrm{n}=117$ & -1.68 to 0.675 \\
\hline Left lateral flexion $(\mathrm{cm})$ & $22.3(4.6), n=116$ & $22.9(4.5), \mathrm{n}=117$ & -1.77 to 0.575 \\
\hline Total spinal flexion-prone $(\mathrm{cm})$ & $9.7(2.5), \mathrm{n}=117$ & $10(2.4), n=113$ & -0.937 to 0.337 \\
\hline Total spinal extension-prone $(\mathrm{cm})$ & $4.1(2.1), n=117$ & $3.8(2.2), n=104$ & -0.27 to 0.87 \\
\hline Straight right leg raised—supine $(\mathrm{cm})$ & 86 (11.5), n=117 & $87.7(9.7), \mathrm{n}=116$ & -4.45 to 1.05 \\
\hline Straight left leg raised—supine $(\mathrm{cm})$ & $86.3(12.1), \mathrm{n}=116$ & $88.3(9.4), n=116$ & -4.8 to 0.803 \\
\hline No (\%) able to sit up with knees flexed, hip/knee flex/ext & $60(52 \%), n=115$ & $52(47 \%), n=110$ & $-8.2 \%$ to $18 \%$ \\
\hline No $(\%)$ able to hold position for 5 seconds & $108(94 \%), n=115$ & $103(93 \%), n=111$ & $-5.4 \%$ to $7.6 \%$ \\
\hline
\end{tabular}


Table 5 Effects of backache on lifestyle in women according to allocation to epidural analgesia or other method of pain relief during labour

\begin{tabular}{lcc}
\hline I stay at home & Epidural $\mathbf{( n = 1 5 1 )}$ & Non-epidural ( $\mathbf{n} \mathbf{1 5 5})$ \\
\hline I change position frequently & 3 & 1 \\
\hline I walk more slowly than usual & 35 & 38 \\
\hline I avoid jobs around the house & 8 & 10 \\
\hline I use handrail to get upstairs & 4 & 2 \\
\hline I lie down and rest more often & 2 & 6 \\
\hline I hold on to something when getting up from a chair & 9 & 12 \\
\hline I get other people to do things for me & 5 & 8 \\
\hline I get dressed more slowly than usual & 6 & 5 \\
\hline I stand for only short periods of time & 6 & 4 \\
\hline I try not to bend down or kneel & 9 & 18 \\
\hline I find it difficult to get out of a chair & 20 & 16 \\
\hline My back is painful most of the time & 11 & 3 \\
\hline It is difficult to turn over in bed & 6 & 13 \\
\hline My appetite is not good & 21 & 0 \\
\hline I have trouble putting socks on & 2 & 6 \\
\hline I only walk for short distances & 8 & 8 \\
\hline I sleep less well & 2 & 21 \\
\hline I get dressed with help from someone else & 21 & 0 \\
\hline I sit down for most of the day & 1 & 19 \\
\hline I avoid heavy jobs around the house & 3 & 14 \\
\hline I am irritable and bad tempered & 15 & 11 \\
\hline I go upstairs more slowly & 10 & 4 \\
\hline I stay in bed for most of the time & 2 & 9 \\
\hline
\end{tabular}

\section{Previous studies}

MacArthur and coworkers reviewed six comparative studies which examined the association between epidural analgesia and postpartum low back pain. ${ }^{15}$ The three studies that showed a significant effect were all retrospective, while the prospective surveys showed no significant differences. ${ }^{16}{ }^{17}$ This important difference in findings illustrates the potential for bias in retrospective studies and similarly supports the value of carefully designed prospective studies, even if it is not feasible to generate a randomised cohort of patients.

\section{Back pain in pregnancy}

We found that reported rates of low back pain were high during pregnancy and at long term follow up in both groups of women. The proportions were similar to those observed by Ostgaard and Andersson in their prospective study of 817 women during pregnancy who were followed up for 12 months or more after delivery. ${ }^{18}$ They found that more than $67 \%$ of women experienced low back pain directly after delivery and $37 \%$ at the later follow up examination. Factors associated with persistent pain were the presence of low back pain before or during pregnancy, physically heavy work, and multiple pregnancy. This figure is somewhat higher than the overall prevalence of low back pain in women in developed countries. ${ }^{15}$ It is also significantly

\section{What is already known on this topic}

Previous research has suggested an association between epidural analgesia during labour and low back pain

It is not known whether this association is causal

What this study adds

This long term follow up study found no evidence of a causal link between epidural analgesia during labour and low back pain higher than the prevalence found in men, which supports the view that pregnancy may influence the development (or course) of low back pain..$^{18-20}$

\section{Further research}

Although our study was powered to detect an absolute difference of $10 \%$ in the incidence of back pain, the findings of almost equal numbers in each group with most outcomes measured means that future controlled comparisons would require many thousands of participants. Given our findings, further research into complications of epidural analgesia will need to be based on large national cohorts of patients to identify risks for rare problems.

This paper is dedicated to Richard Johanson, who died a few months before publication. Dr G Waddell gave advice on methodology. We are grateful to all the women who participated.

Contributors: The study was conceived by $\mathrm{CJH}$ and RBJ. $\mathrm{CJ}$, TD, KD, PWJ, and RBJ contributed to the design. CJH and RBJ supervised the execution of the study. TD collected the data. LL was data manager. PWJ and LL analysed the data. The paper was written jointly by all authors. $\mathrm{CJH}$ is guarantor.

Funding: National Back Pain Association. RJ, KD, and LL's clinical trials activities are supported by grants from the NHS(E) West Midlands research and development programme.

Competing interests: None declared.

1 Chamberlain G, Wraight A, Steer P. Pain and its relief in childbirth. The results of a national survey conducted by the National Birthday Trust. Edinburgh: Churchill Livingstone, 1993.

2 Scott DB, Hibbard BM. Serious non-fatal complications associated with extradural block in obstetric practice. Br J Anaesth 1990;64:537-41.

3 MacArthur C, Lewis M, Knox EG, Crawford JS. Epidural anaesthesia and long term backache after childbirth. BMJ 1990;301:9-12.

4 Russell R, Groves P, Taub N, O'Dowd J, Reynolds F. Assessing long term backache after childbirth. BMJ 1993;306:1299-303.

5 MacArthur C, Knox G, Lewis M. Epidural analgesia during childbirth. Association with backache is real. BMJ 1993;307:64.

6 MacLeod J, Macintyre C, McClure JH, Whitfield A. Backache and epidural analgesia. Int J Obstet Anaesth 1995;4:21-5.

7 Waddell G, Allan DB, Newton M. Clinical evaluation of disability in back pain. The adult spine: principles and practice. New York: Raven Press, 1991:155-68.

8 Howell CJ, Kidd C, Roberts W, Upton P, Lucking L, Jones PW, et al. A randomised controlled trial of epidural compared with non-epidura analgesia in labour. Br J Obstet Gynaecol 2001;108:27-33.

9 Roland M, Morris R. A study of the natural history of back pain. Part 1: development of a reliable and sensitive measure of disability in low-back pain. Spine 1983;8:141-4.

10 Waddell G, Somerville D, Henderson I, Newton M. Objective clinical evaluation of physical impairment in chronic low back pain. Spine 1992;17:617-28.

11 Macrae IF, Wright V. Measurement of back movement. Ann Rheum Dis 1969;28:584-9.

12 Gauvin MG, Riddle DL, Rothstein JM. Reliability of clinical measurements of forward bending using modified fingertip-to-floor method. Phys Ther 1990:70:443-7.

13 Howell CJ. Epidural vs non epidural analgesia for pain relief in labour. Cochrane Database Syst Rev 2000;(3):CD000331.

14 Moher D, Schulz KF, Altman DG, for the CONSORT Group. The CONSORT statement: revised recommendations for improving the quaity of reports of parallel-group randomised trials. Lamcet 2001:357:1191-4.

15 Macarthur AJ, Macarthur C, Weeks SK. Is epidural anesthesia in labor associated with chronic low back pain? A prospective cohort study. Anesth Analg 1997;85:1066-70.

16 Breen TW, Ransil BJ, Groves PA, Oriol NE. Factors associated with back pain after childbirth. Anesthesiology 1994;81:29-34.

17 Macarthur A, Macarthur C, Weeks S. Epidural anaesthesia and long term back pain after delivery: a prospective cohort study BMJ 1995;311:1336-9.

18 Ostgaard HC, Andersson GB. Postpartum low-back pain. Spine 1992;17:53-5.

19 Svensson HO, Andersson GBJ, Hagstad A, Jansson PO. The relationship of low-back pain to pregnancy and gynecologic factors. Spine 1990;15:371-5.

20 Orvieto R, Achiron A, Ben-Rafael Z, Gelernter I, Achiron R. Low-back pain of pregnancy. Acta Obstet Gynecol Scand 1994;73:209-14.

(Accepted 21 March 2002) 